\title{
Haicai: uma experiência pedagógica com turmas de EJA
}

Ires Figueiredo Souza'

\section{Resumo}

O presente trabalho apresenta os resultados de uma prática docente sobre o gênero literário haicai em duas turmas de Educação de Jovens e Adultos (EJA) de um projeto de extensão da Universidade Federal de Minas Gerais (UFMG) - Projeto de Ensino Fundamental de Jovens e Adultos $-2^{\circ}$ Segmento (Proef 2). O objetivo foi incentivar a escrita criativa dos alunos, instigar a leitura de poesias e, também, inserir os alunos no mundo da literatura. As produções apresentaram conteúdos políticos, sociais, pessoais e artísticos. Ao final, os alunos mostraram-se motivados a continuar lendo e escrevendo haicais.

\section{Palavras-chave}

Haicai. Jovens e Adultos. Leitura. Escrita.

1. Graduanda em Letras (Licenciatura em Português) pela Universidade Federal de Minas Gerais; atuou como bolsista no Projeto de Ensino Fundamental de Jovens e Adultos - $2^{\circ}$ segmento (Proef 2). E-mail: iresfs@hotmail. com. 


\title{
Haiku: a pedagogical experience in youth and adult education
}

Ires Figueiredo Souza*

\begin{abstract}
This paper presents the results of a teaching practice on the literary genre haiku experienced in two Youth and Adults Education groups. Classes were held in an extension project of the Federal University of Minas Gerais called Project for Projeto de Ensino Fundamental de Jovens e Adultos $-2^{\circ}$ Segmento - Proef 2 (Elementery Youth and Adults Education - 2nd part). The purpose of the project was to encourage poetry reading, creative writing, and to introduce the students in the literary world. Many students felt motivated to continue writing haiku. Moreover, the students' written productions were very interesting and had political, social, personal and artistic contents.
\end{abstract}

\section{Keywords}

Haiku. Youth and Adult Education. Reading. Writing.

\footnotetext{
* Portuguese Language and Literature student, Federal University of Minas Gerais, State of Minas Gerais, Brazil; she participated of the Projeto de Ensino Fundamental de Jovens e Adultos $-2^{\circ}$ Segmento - Proef 2 (Project for Elementary Youth and Adults Education - 2nd part). E-mail: iresfs@hotmail.com.
} 


\section{Introdução}

A Educação de Jovens e Adultos (EJA), no que tange ao ensino de língua portuguesa, se difere do ensino regular. Podemos afirmar isto pelo fato da demanda pedagógica da EJA ser diferente. Afinal, o que buscam os alunos adultos quando voltam à sala de aula? Para responder essa questão, recorremos a Oliveira, que afirma:

O jovem tem um olhar para o futuro. $\mathrm{Na}$ transição da infância para a fase adulta está ligado às inovações tecnológicas, aos modismos dos meios de comunicação, ou seja, às mudanças que ocorrem no mundo. $\mathrm{O}$ adulto está interessado na vida profissional, na sua inserção no mercado de trabalho, olhando para a sua situação de vida presente. O idoso busca ser cidadão, viver a sua vida em sociedade, sendo respeitado como pessoa e pelo seu passado, pela sua história de vida. Almeja viver na sociedade com dignidade. (OLIVEIRA, 2004, p. 59-60).

Os alunos adultos têm objetivos e visões diferentes dos alunos jovens. Quando um adulto volta para a escola, ele quer uma oportunidade de inserção na sociedade letrada e de conhecimentos que vão além de conteúdos. Para tanto, o educador da EJA precisa ter práticas diferenciadas para atender a demanda desses sujeitos. Ademais, é preciso compreender o que é a educação de adultos e como lidar com esta modalidade de ensino em termos didáticos. Segundo Paulo Freire,

O conceito de Educação de Adultos vai se movendo na direção de educação popular na medida em que a realidade começa a fazer algumas exigências à sensibilidade e à competência científica dos educadores e das educadoras. Uma destas exigências tem que ver com a compreensão crítica dos educadores do que vem ocorrendo na cotidianidade do meio popular. Não é possível a educadoras e educadores pensar apenas os procedimentos didáticos e os conteúdos a serem ensinados aos grupos populares. Os próprios conteúdos a serem ensinados não podem ser totalmente estranhos àquela cotidianidade. (FREIRE, 2001, p. 16).

Diante de tal afirmação, e repensando todo o processo linguístico da língua portuguesa, é imprescindível que a disciplina proporcione aos alunos da EJA a capacidade escrita, linguística e oral e, para tanto, não é necessário se prender a métodos tradicionais e gramaticais. O professor de português precisa buscar mecanismos que proporcionem uma forma de compreensão da língua que não esteja focada apenas no conteúdo e contribua para a inserção do aluno na sociedade letrada, a fim de que ele tenha acesso aos direitos públicos e sociais, como todos os demais cidadãos.

O domínio da língua tem estreita relação com a possibilidade de plena participação social, posto que por meio dela o homem comunica-se, tem acesso à informação, expressa e defende pontos de vista, partilha ou constrói visões de mundo e produz conhecimento. Assim, um projeto educativo comprometido com a democratização social e cultural atribui à escola a função e a responsabilidade de garantir a todos os seus alunos o acesso aos saberes linguísticos necessários para o exercício da cidadania, direito inalienável de todos, conforme os Parâmetros Curriculares Nacionais: Língua Portuguesa.

Dessa forma, com o intuito de incentivar a escrita criativa dos alunos, instigar a leitura de poesias e, também, inserir os alunos no mundo literário, resolvemos trabalhar o gênero haicai em duas turmas de EJA do Proef 2. 


\section{Caracterização do projeto}

O Proef-2 foi criado em 1986 e oferece aos servidores da UFMG e pessoas da comunidade a oportunidade da escolarização básica, com avaliação no processo e certificado expedido pela Escola de Ensino Básico do Centro Pedagógico da UFMG. Trata-se de um projeto de extensão que se constitui como um espaço de formação docente, pois conta com a monitoria de 24 alunos de licenciaturas da UFMG orientados por professores da instituição. Esses licenciandos têm a oportunidade de vivenciar a realidade da sala de aula, intensificando sua formação como professores ao participar de projetos como esse promovido pela universidade.

\section{Descrição da experiência}

A experiência aqui apresentada foi realizada durante o segundo semestre de 2013, em três aulas (com uma hora de duração cada), com duas turmas de EJA - uma com 23 alunos e outra, com 14 - ambas concluintes do Proef 2, sendo, portanto, os alunos que iriam para o ensino médio no próximo ano.

$\mathrm{Na}$ primeira aula, perguntei se eles sabiam o que era haicai ${ }^{2}$, se conheciam ou tinham ouvido falar. Em ambas as turmas, nenhum aluno conhecia o gênero. Então, expliquei a eles sobre o haicai, sua origem, sua forma e seu significado. Para tanto, lemos alguns de Bashô, fundador da poesia haicai como é atualmente conhecida. Em seguida, entreguei aos estudantes alguns exemplares de Helena Kolody, ressaltando sua notoriedade, visto ser ela a primeira mulher no Brasil a escrever haicais, e outros de Paulo Leminski ${ }^{3}$, grande colaborador do gênero no Brasil. Após apresentar os autores, lemos os haicais e começamos a analisar seu conteúdo, suas palavras, formas e elementos. Os alunos se mostraram extremamente empolgados com os poemas e gostaram muito, principalmente dos que apresentavam rimas. As interpretações e opiniões dos educandos sobre as leituras tiveram grande contribuição e importância para a aula, pois mostraram a leitura de mundo deles por meio da poesia. Além disso, para nossa surpresa, os alunos notaram diferença entre os haicais de Bashô e os dos poetas brasileiros trabalhados. Foi explicado que o haicai brasileiro adquiriu um novo formato com o tempo e não versava apenas sobre natureza e/ ou apresentava a regra de dezessete sílabas.

Foi gratificante perceber o interesse

3. Sobre o haicai, cabem aqui algumas considerações. O haiku, traduzido para o português como haicai, é a forma de poesia mais tradicional da cultura japonesa. Segundo Franchetti (1991, p. 11) as regras do haicai são "ser uma estrofe longa, de dezessete sílabas; conter sempre uma referência à estação do ano e ao lugar onde se realizou a sessão; e, ser sintaticamente completo, independente da estrofe seguinte". Dessa forma, forma-se poesia de três versos ou frases de 5, 7 e 5 sílabas. O grande mestre de haicai no renga do século XVII e fundador da poesia do haicai como é conhecida hoje é Matsuo Bashô (1644-1694), também considerado o mais sofisticado praticante de haicai e quem mais filosofou sobre o tema. Foi o poeta mais famoso do período Edo no Japão. O haicai alcançou o Brasil em 1908, no primeiro levante imigratório japonês que aportou no país. (PORTELA, 2003, p. 168). A primeira menção positiva ao haicai no Brasil deve-se a Afrânio Peixoto. Num volume de 1919, intitulado Trovas Populares Brasileiras, assimilando a forma japonesa à trova popular, Peixoto apresentava o haicai como um "epigrama lírico", reconhecendo nele não a bizarrice da forma, mas um "encanto intraduzível". Contudo, após Afrânio houve outros poetas que colaboraram no percurso do haicai pelo Brasil por distintos momentos da história literária. Entre esses tempos históricos situa-se a produção de dois autores que tornaram o haicai definitivamente popular no país: Paulo Leminski e Millôr Fernandes (FRANCHETTI, 2008).

4. Muitos haicais foram moldados ao gosto de seu praticante, conforme as influências literárias de sua cultura. Helena Kolody e Paulo Leminski apresentam haicais diferentes das regras do haicai tradicional. Os haicais de Helena utilizam títulos, às vezes usam rimas, métrica, linguagem poética. Já os haicais de Leminski são livres e não apresentam métrica, quase não apresentam rimas, contendo ironia e senso de humor. 
dos alunos sobre um tema novo e observar seu aprendizado. Para colocar a imaginação dos alunos em prática e instigar ainda mais o interesse deles, sugerimos três temas - amor, Brasil e escola - para que eles escrevessem um haicai sobre cada um. A escolha foi aleatória. Os alunos ficaram receosos no início e duvidando de suas próprias capacidades quanto à escrita. Contudo, recomendamos que ficassem à vontade para escrever seus haicais, que poderiam ser rimados ou não, extensos ou curtos, desde que com três versos. Os resultados seriam mostrados na aula seguinte.

No segundo dia de aula, pedimos aos alunos que lessem em voz alta os haicais produzidos por eles na aula anterior. A maioria se mostrou tímida, pois disseram que os haicais não estavam "bons". Insistimos, ainda assim, para que lessem. Ficamos surpresas com a escrita criativa dos alunos. Inicialmente, nosso objetivo era instigá-los a escrever, mas os alunos demonstraram ser suficientemente criativos para a escrita poética; sendo necessário apenas darIhes a oportunidade para mostrar seu potencial.

Os haicais dos alunos ficaram muito interessantes e diversificados, com ou sem rimas, engraçados ou com um teor mais social e político, dentro do tema "Brasil". Foi uma grande surpresa. Poderíamos ter terminado o conteúdo e considerar a experiência suficiente, mas ao ver a capacidade imaginativa e criativa dos alunos, resolvemos continuar por mais um dia. Além disso, eles mostraram mais confiança para escrever poesias e maior interesse em haicais.

No terceiro e último dia, resolvemos trabalhar haicais com temas livres. Os alunos tiveram meia hora para saírem da sala e observarem algum objeto, lugar, ser ou algo que Ihes chamassem a atenção para que, em sala, pudessem produzir um haicai por meio da observação direta. O resultado desta aula foi ainda mais surpreendente: os alunos escreveram poesias sensacionais. Como a produção dos poemas foi muito positiva, resolvemos recolhê-los para uma possível publicação. Além disso, a motivação foi ainda maior quando eles viram que eram capazes de escrever poemas tão profundos e bonitos. Apesar do pouco tempo, já que as aulas duraram apenas uma hora, os resultados foram muito satisfatórios. Abaixo, são apresentados alguns exemplos das produções dos alunos: 
Figura 1 - Produção do aluno A.

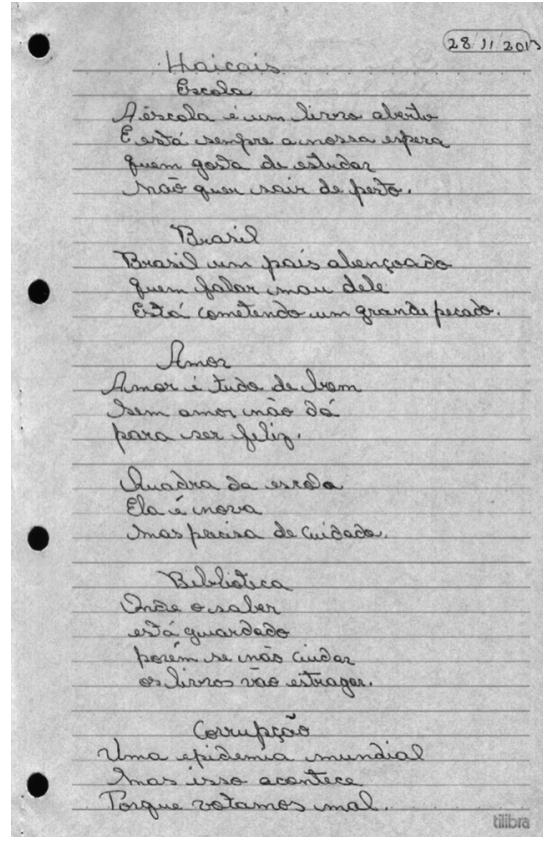

Fonte: Acervo da autora (2013).
Figura 2 - Produção do aluno B.

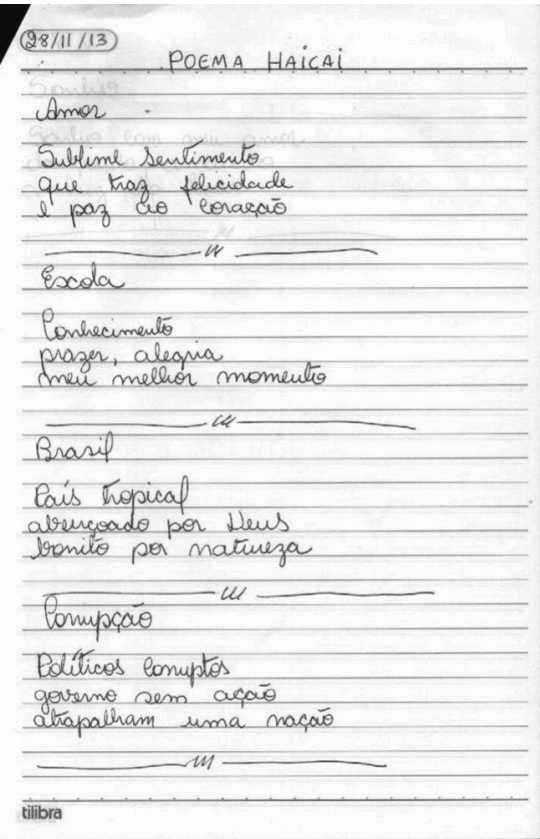

Fonte: Acervo da autora (2013).

Figura 3 - Produção do aluno C.

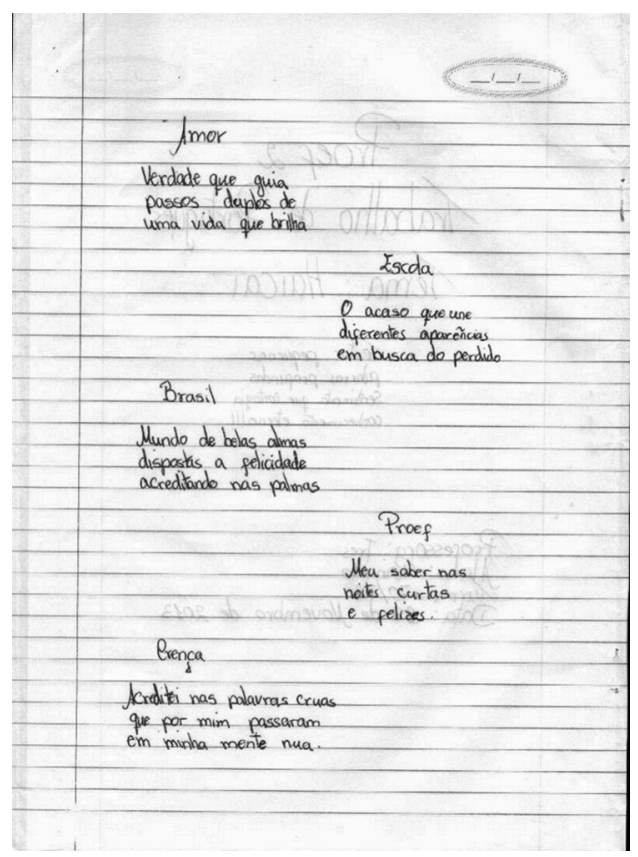

Fonte: Acervo da autora (2013). 


\section{Considerações finais}

A experiência em ministrar um conteúdo como o haicai para as turmas de EJA foi satisfatória, visto que os alunos puderam compreender este gênero literário. A partir de suas próprias poesias, esses alunos sentiramse motivados para pesquisar outros haicais, ler poemas e continuar a praticar a escrita criativa.

As aulas de português, em muitas instituições escolares, são trabalhadas com foco apenas no conteúdo e se baseiam em gramática, leitura em voz alta e interpretação de textos. Assim, muitos alunos têm uma opinião negativa da disciplina ou, por vivenciar sempre a mesma didática disciplinar, acham que português é apenasgramática. A prática daaprendizagem pelo aluno da EJA vai além da aquisição da gramática:

Quem procura cursos de alfabetização de adultos quer aprender a escrever e a ler sentenças, frases, palavras, quer alfabetizarse. A leitura e a escrita das palavras, contudo, passa pela leitura do mundo. Ler o mundo é um ato anterior à leitura da palavra. O ensino da leitura e da escrita da palavra a que falte o exercício crítico da leitura e da releitura do mundo é, científica, política e pedagogicamente, capenga. (FREIRE, 1992, p. 79).

Assim, o educador precisa ir além da gramática, do conteúdo e da leitura didática. É preciso considerar a leitura de mundo e da realidade que o aluno vivencia diariamente. A escola precisa se preocupar em alfabetizar cidadãos que atuarão na sociedade. Precisamos ser mais do que professores, é preciso que sejamos educadores sociais. Nessa perspectiva é que propusemos trabalhar com haicais nas turmas de jovens e adultos. O objetivo era que os alunos vissem o português para além da gramática e que conseguissem expressar sentimentos, experiências, conhecimentos de mundo e escrita criativa nas suas produções e, com isto, adquirissem mais autoconfiançae descobrissem o prazer pela leitura.

Como os haicais são poesias menores, podendo versar sobre qualquer assunto, os alunos se interessam muito pelo gênero. Tratase de uma proposta pedagógica que pode ser realizada em turmas de jovens e adultos, mas também com crianças e adolescentes. $\mathrm{O}$ diferencial da atividade foi a ideia da produção de um livro com os haicais escritos pelos alunos.

A realização deste projeto nos proporcionou a reflexão sobre o que é ser educador. Concluímos que para além de professores, temos sempre que procurar formas alternativas para atuarmos como educadores sociais. Neste sentido, Carvalho e Baptista (2004) afirmam que, como educador, o educador social confrontará o outro com projetos de vida alternativos, procurando sempre viabilizar as suas opções, incluindo nestas, a possibilidade de construção de projetos autônomos quanto ao seu sentido. $\mathrm{O}$ questionamento, a ponderação e a implicação surgirão, então, como estratégias privilegiadas de aprofundamento da identidade individual.

Quando nos tornarmos educadores sociais, devemos sempre buscar a realização de projetos educacionais e pedagógicos, que se relacionam com o conhecimento de mundo do aluno da EJA. Devemos ter estratégias didáticas que colaborem na autonomia do aluno adulto para que ele atue melhor na comunidade em que vive. Contudo, o educador social precisa ter uma formação contínua, procurando sempre melhorar, atualizar e refletir sobre sua atuação social e educacional.

\footnotetext{
A formação contínua, sobretudo para um educador, é - terá de ser-, por isso, a vivência consequente de atitudes que the permitam partilhar a curiosidade, fruir a descoberta, organizar as iniciativas, evoluir, promoverse para que, formando-se, se transforme ajudando a formar os outros - os educandos! - pelo contágio operado por essa formação,
} 
a partir daí entendida como um autêntico projeto de vida. (CARVALHO; BAPTISTA, 2004, p. 89).

A partir da formação contínua, a exemplo da EJA, é possível colaborar na formação dos educandos adultos. O educador social precisa vivenciar e buscar iniciativas para seu melhoramento constante e, dessa forma, ser um educador que colabora com a autonomia e a participação social dos alunos adultos.

\section{Referências}

CARVALHO, A. D. de; BAPTISTA, I. Educação social: fundamentos e estratégias. Porto, Portugal: Porto Editora, 2004 (Coleção Educação e Trabalho Social).

FRANCHETTI, P. O haicai no Brasil. Alea, v. 10, n. 2, jul./dez. 2008. Disponível em: < http:// www.scielo.br/scielo.php?script=sci_arttext\&pid=S1517-106X2008000200007>. Acesso em: 14 de jun. 2014.

FRANCHETTI, P.; DOI, E. T.; DANTAS, L. Haikai: antologia e história. 2. ed. Campinas, SP: Editora da Unicamp, 1991.

FREIRE, P. Pedagogia da esperança: um reencontro com a pedagogia do oprimido. Notas: Ana Maria Araújo Freire. Rio de Janeiro: Paz e Terra, 1992.

Política e Educação: ensaios. 5. ed. São Paulo: Cortez, 2001.

OLIVEIRA, I. A. Princípios pedagógicos na educação de jovens e adultos. Revista da Alfabetização Solidária, v. 4, n. 4, São Paulo: Unimarco, 2004.

PORTELA, J. C. Semiótica do haikai: por uma didática da poesia. 2003. 135f. Dissertação (Mestrado em Letras) - Centro de Letras e Ciências Humanas, Universidade Estadual de Londrina, Londrina, 2011.

Submetido em 5 de abril de 2014.

Aprovado em 9 de julho de 2014. 